\title{
From Marginalized to
} Maximized Opportunities for Diverse Youths With Disabilities

\section{A Position Paper of the Division on Career Development and Transition}

\author{
Audrey A. Trainor \\ University of Wisconsin-Madison \\ Lauren Lindstrom \\ University of Oregon, Eugene \\ Marlene Simon-Burroughs \\ U.S. Department of Education, Washington, DC \\ James E. Martin \\ University of Oklahoma, Norman \\ Audrey McCray Sorrells \\ University of Texas at Austin
}

\begin{abstract}
Current secondary education and transition practices have created differential education and employment outcomes by gender, race and ethnicity, socioeconomic status, and disability classifications. These differential outcomes result in economic and social marginalization of far too many students with disabilities. Transition education practices need to respond to these differential outcomes and provide targeted, systematic, and long-term opportunities for all students to attain individually and family-determined postschool goals. This position paper recommends an ecological framework for considering the multiple systems that influence transition education and postschool outcomes for diverse youths with disabilities. The authors argue for educators, researchers, and policy makers to attend to social, political, economic, educational, and cultural contexts in developing effective interventions and improving postschool outcomes.
\end{abstract}

Keywords: diversity; postsecondary outcomes; equity; culturally responsive education; transition

$\mathrm{N}^{2}$ avigating the transition from high school to employment, postsecondary education, and other adult roles is a complex and challenging process for youths with disabilities (Kohler \& Field, 2003). During the past two decades, educators, researchers, and policy makers have focused a great deal of attention on improving transition services and postschool outcomes (Johnson, Stodden, Emanuel, Luecking, \& Mack, 2002). Much progress has been made; however, pressing needs and gaps in services still exist (Coutinho, Oswald, \& Best, 2006). This position paper calls attention to the unique career development and transition education needs of culturally diverse youths with disabilities and urges members of our community to improve practice and expand research on the social, political, educational, economic, and cultural contexts within which students with disabilities live, become educated, and work. We believe that improvements in transition education and outcomes will only result from the development and implementation of systemic changes.

The Division on Career Development and Transition (DCDT) affirms the value of preparing all youths with disabilities for successful postschool employment and educational experiences. We believe it is crucial to develop and use transition education practices that result in more equitable outcomes for diverse youths with

Authors' Note: The opinions expressed herein do not necessarily reflect the policy of the U.S. Department of Education, and no official endorsement should be inferred. 
disabilities. This position paper provides an introduction to the issues facing culturally and linguistically diverse youths. We then define challenges in need of immediate attention using an ecological framework to summarize issues that range from the micro- to macro-systems. Last, we identify gaps in the literature and present an agenda for future transition education practice, research, and advocacy.

\section{Cultural Diversity}

"Culturally diverse" is a deceptively simplistic term. Today's students with disabilities are culturally diverse based on racial/ethnic identities, religion and traditions, and socioeconomic backgrounds. Diversity also includes majority culture (i.e., European American) youths, some of whom face economic marginalization and lack of opportunity because of poverty or other circumstances. A culture of disability also exists and interacts with the environment to define cultural identities. Similarly, gender and disability interact as is evidenced in differential outcomes. Research suggests that cultural identities influence, not dictate, our behavior; they are dynamic, multifaceted, and shared by group members (Garcia \& Dominguez, 1997). Cultural identities make life secure and meaningful (Banks, 2004), and knowledge of culture provides a sense of power (Delpit, 1995). Culture allows us to maintain our sense of identities and perceptions of self and represents the lenses by which we view and evaluate the motives, thoughts, and behaviors of others (Neal, McCray, Webb-Johnson, \& Bridgest, 2003). History tells us that cultural identities can be markers of power and status. Positions such as cultural outsiders and insiders contribute to our perceptions and experiences (Banks, 2004).

Given our own evolving understandings of the complexities and multifaceted dynamics of cultural diversity, we consider the inclusive and interacting nature of the term, including gender (Asch, Rousso, \& Jefferies, 2001) and disability (Brown, 1996) as culture-bound identities with shared histories of oppression, exclusion, underachievement, and differentiated or poor outcomes. As a cultural group, for example, women with physical disabilities, African American men with emotional disturbance, European American men who are deaf, and Latinos with language disorders may experience outcomes that cannot neatly be categorized as race/ethnicity, culture, or disability. Yet as Brown (1996) contended, individuals with disabilities often have to struggle to determine their primary cultural or contextual identity.
We assert that disability and difference are inherently both cultural and contextual and necessarily require examination within the discourse of race, ethnicity, language, socioeconomic class, and gender to improve transition education and reduce individual and collective marginalization in research, policy, and practice. In this position paper, therefore, we are concerned primarily with African American, Latino, Asian American/Pacific Islander, and Native American Indian youths, as well as youths with disabilities of all races/ethnicities who are from low socioeconomic backgrounds. We also are concerned about youths who speak English as a second language and/or have undocumented or immigrant status, as well as gender-specific differentiated outcomes.

The lack of understanding and inadequate attention to cultural diversity concerns us because research suggests that different groups of students with disabilities experience disparate postsecondary outcomes. For example, we know that high school graduation rates and postschool employment outcomes for youths with disabilities differ by disability category, socioeconomic status, gender, and race/ethnicity (Wagner, Newman, Cameto, Garza, \& Levine, 2005). The extent to which differences in outcomes signify barriers to equitable transitions is complex and requires sophisticated analysis not only of multiple variables but, we believe, multiple systems of variables as well as interactions within and between systems. We are concerned that the existing transition literature does not adequately address sociocultural influences on access, opportunities, or outcomes, nor does it comprehensively address interactions among people, groups, and institutions. This lack of attention results in persistent marginalization of culturally diverse and low-income youths with disabilities.

\section{Disparate Postschool Outcomes}

Growing ethnic and linguistic diversity in the United States has resulted in corresponding changes in public schools. In 2004, the racial/ethnic distribution of students in Kindergarten through 12th grade was 57\% European American, 19\% Latino, 16\% African American, 4\% Asian American/Pacific Islander, and 3\% other (U.S. Department of Education, 2006). Only two decades earlier, African American, Latino, Asian American, and other children of color together comprised only $28 \%$ of the school-age population, about two thirds of the $42 \%$ of the population they comprised in 2004.

If all schools in all regions, across rural, suburban, and urban settings, graduated youths across socioeconomic, 
racial/ethnic, gender, and disability groups with similar postsecondary outcomes, the need for this article would not exist. Students, families, schools, and communities continue to struggle to achieve equitable postschool outcomes. For example, $95 \%$ of Asian Americans complete high school, and the same is true for $92 \%$ of European Americans, $85 \%$ of African Americans, and 69\% of Latinos (U.S. Department of Education, 2003). Highpoverty schools report low student math and reading achievement, as well as high enrollments of children of color. Given the disparity of access to high-quality educational opportunities in the form of experienced teachers and material resources, these differences are not surprising. Urban youths are more likely to receive instruction from the least experienced teachers (U.S. Department of Education, 2007) and more likely to attend schools with low per-pupil expenditures.

Reports from the second National Longitudinal Transition Study (NLTS2) illustrate that youths' experiences during the transition to adulthood have changed in significant ways since the first 1980-era longitudinal study. Youths with disabilities today are more likely to have obtained paid employment after high school (Wagner, Newman, Cameto, \& Levine, 2005). Although youths across three ethnicities (European American, African American, and Latino) made gains in both employment status and wages earned, group differences persist. In 2003, about 74\% of European American youths with disabilities had been employed since high school, whereas the same was true for $62 \%$ and $65 \%$ of African Americans and Latinos, respectively (Wagner, Newman, Cameto, \& Levine, 2005). Furthermore, 90\% of working European American youths with disabilities were earning above-minimum wage, compared with $77 \%$ of African American and $69 \%$ of Latino youths.

Ethnicity is but one of many demographic factors that deserve consideration when we engage in discussions about diversity and transition. We need to also attend to the potential influences of disability, socioeconomic status, and gender on opportunities and outcomes for certain youths. NLTS2 reports indicate clear differences in graduation, postsecondary enrollment, and employment by disability category. For instance, students with vision impairments have a relatively high enrollment in postsecondary schools $(69 \%)$, whereas students with emotional and behavior disabilities (about 21\%) have much lower enrollment rates (Wagner, Newman, Cameto, Garza, et al., 2005). Postsecondary enrollment also varies by factors associated with socioeconomic status. According to the NLTS2, youths with disabilities who have at least one parent who has a bachelor's degree are $11 \%$ more likely to enroll in a postsecondary educational setting than their peers with disabilities who do not have a parent with a college degree. Previous researchers have also documented poor postschool employment and lack of transition education opportunities for young women with disabilities (Asch et al., 2001; Lindstrom \& Benz, 2002). In addition, African American men continue to face disproportionate representation in special education programs for emotional and behavior disabilities and subsequent lower completion in secondary education (Harry \& Klingner, 2006; McCray Sorrells, Webb-Johnson, \& Townsend, 2004); disproportionately low rates of enrollment in postsecondary education (U.S. Department of Education, 2003); disproportionate employment and wage inequities (Bureau of Labor Statistics, 2006); disproportionate rates of juvenile delinquency and incarceration (Sickmund, 2004); and, in some U.S. regions, higher death sentences (James R. Patton, personal communication, August 14, 2007).

We believe that disparate transition education opportunities and postschool outcomes are likely the result of multiple factors. Understanding the relationship between students' demographic characteristics and group outcomes apprises us of the national transition landscape, but it does little to explain why these differences exist. Transition research and practice needs a complex framework that extends our understanding of individual transition outcomes into the contexts and opportunity dimensions in which they occur. In this article, we build on extant literature that uses an ecological approach to create opportunities for improved transition education research and practice (Garcia \& Dominguez, 1997; GilKashiwabara, Hogansen, Geenen, Powers, \& Powers, 2007; Mithaug, 1996) and posit that an ecological framework provides an essential tool for both improved transition education and advocacy for youths from low socioeconomic and culturally diverse groups.

\section{Defining the Micro to Macro Issues}

A nascent multicultural transition education literature base presents a growing body of evidence that cultural identity and values guide and influence youths and their families (deFur, Todd-Allen, \& Getzel, 2001; Trainor, $2005,2007)$. A lack of awareness of the impact of cultural values and beliefs on transition is another concern (Valenzuela \& Martin, 2005). Conflict of values and beliefs between diverse youths with disabilities and educators may create additional barriers to successful transitions, as would conflict between current and future postschool cultures. Yet few transition studies have examined these areas. 
We believe that ecological theory provides a useful tool for considering multicultural issues in educational contexts (Chronister, McWhirter, \& Kerewsky, 2004; Garcia \& Dominguez, 1997; Gil-Kashiwabara et al., 2007) and offers a model to better understand and improve the marginalized school and postschool outcomes experienced by many youths with disabilities. Using Bronfenbrenner's (1979) model of ecological development as our guiding framework, we organize a review of the literature regarding transition for diverse youths with disabilities in an attempt to answer two basic questions, What do we already know about transition education for youths from diverse groups? and What issues continue to need attention to improve transition services and postschool outcomes? We approach this task from within a series of concentric circles, moving from microsystem aspects of transition in an outwardly fashion, toward the macrosystem, or "big picture." For all youths, interactions in every context may affect individual, family, school, and community in both circuitous and linear fashions, improving or impeding school and postschool success.

\section{Microsystem}

The microsystem includes people who are in direct contact with a student, such as family members, school staff, and peers (Chronister et al., 2004). Interactions between youths with disabilities and their family members have been a focus of transition research at the microsystemic level, particularly in studies that have examined transition experiences of culturally and linguistically diverse youths. Gil-Kashiwabara et al. (2007) examined microsystemic interactions and found that parents of Latinas with disabilities emphasized college as a postschool outcome for their daughters. These researchers also found that disruptions in family functioning such as high rates of mobility have deleterious effects on child-parent relationships that are important during adolescence. Parental influence on transition opportunities of diverse youths is a key in successful outcomes (Geenen, Powers, \& Lopez-Vasquez, 2005).

School settings where students with disabilities receive instruction represent another microsystem that has immediate impact on shaping school and postschool outcomes (Bronfenbrenner, 1979). Instructional opportunities facilitate or hinder school and postschool success. Transition education practices must increase microsystem opportunities for students with disabilities to increase their self-determination skills as a foundation for school and postschool success (Shogren et al., 2007). Mithaug's (1996) equal opportunity theory suggests that instructional activities should increase students' skills and opportunities for self-determination. Increasing student engagement in individualized education program (IEP) meetings increases students' self-determination skills (Martin et al., 2006). Self-determined students establish goals from an awareness of their needs and interests, then develop plans, implement the plans, selfevaluate progress, and make needed adjustments to attain their goals (Martin \& Marshall, 1995).

A growing body of research suggests strong relationships between self-determination and postschool outcomes. Increased self-determination skills increase academic performance (Konrad, Fowler, Walker, Test, $\&$ Wood, 2007; Martin et al., 2006). Self-determination attributes predicted post-high school success, and students who identify postschool goals during early adolescence may experience better postschool outcomes (Goldberg, Higgins, Raskind, \& Herman, 2003). College students with learning disabilities who had higher selfdetermination scores obtained better grades than students with lower scores (Sarver, 2000) and higher employment rates (Wehmeyer \& Palmer, 2003).

Despite a growing number of studies demonstrating positive outcomes of increased self-determination skills, teachers report knowing little about self-determination and how to implement self-determination instruction in their classroom (Wehmeyer, Agran, \& Hughes, 2000). Interrelationships between culture, transition education, self-determination opportunities, and the IEP process influence postschool outcomes for culturally diverse students with IEPs (Leake \& Boone, 2007). Practitioners need to know how best to involve culturally diverse families and students with IEPs in transition planning and to facilitate self-determination, but there is no empirical guidance on how to do this.

\section{Mesosystem}

The mesosystem refers to interconnections between the various microsystems, such as home-school interactions or teacher-rehabilitation counselor communications. The ecological model assumes that individual development and achievement will be enhanced if communication between microsystems is consistent and positive (Bronfenbrenner, 1979). Communication and coordination across settings is crucial for academic, employment, and postschool success (Benz, Johnson, Mikkelsen, \& Lindstrom, 1995).

According to federal policy (Individuals With Disabilities Education Improvement Act [IDEIA], 2004), teachers and administrators must provide opportunities for parents to participate in school-related services and educational decision making. This mandate is based on a 
premise of equity, individual rights, and collaborative decision making between school personnel and families (Kalyanpur, Harry, \& Skrtic, 2000). Yet the "realization of this vision of collaborative relationships and familycentered practice remains elusive, particularly for lowincome and culturally diverse families" (Kalyanpur et al., 2000 , p. 119). A number of barriers have the potential to limit active parent involvement in special education for members of diverse groups. Researchers have noted a lack of effort on the part of special education professionals to seek out family input (Harry, Allen, \& McLaughlin, 1995) and a tendency for teachers to schedule planning meetings at times that may be inconvenient or impossible for working parents to attend (Geenen et al., 2005). Language differences can also create barriers for families when written materials are provided only in English and/or translators are not present at meetings or conferences. A history of unsatisfactory home-school relationships and/or differing beliefs about education, disability, and teacher expertise and authority influence parent involvement (Harry et al., 1995).

Similar barriers and issues have emerged from the literature focusing on family involvement in career development and transition planning (Blustein et al., 2002). Within the school system, bureaucratic barriers such as a lack of information regarding transition planning or community resources limit opportunities for parent partnerships (Geenen et al., 2005). Teachers may lack effective communication strategies (Greene \& Nefsky, 1999) or disregard student or family cultural values (deFur et al., 2001). Many parents from diverse groups have reported feeling mistrusted, misunderstood, and unsupported by professionals during the transition process (deFur et al., 2001; Greene \& Nefsky, 1999). Finally, contextual barriers facing many families such as long working hours, time conflicts, single parenting, transportation, and child care difficulties prevent parents from being able to actively engage in school transition planning structures and intentional career-related activities (Bluestein et al., 2002; deFur et al., 2001). These barriers to family-school partnerships create inequities and contribute to differential postschool outcomes.

\section{Exosystem}

The exosystem includes system-level issues and interactions across multiple settings, for example, between community and school. However, students with disabilities are typically not active participants in these interactions. Nevertheless, these interactions affect students' daily lives. The distribution of educational resources, local implementation of education policy, and specific practices of local schools are all examples of exosystemic interactions (Garcia \& Dominguez, 1997). The implementation of national education policies such as No Child Left Behind (NCLB) and IDEIA have implications for transition education. Although IDEIA includes specific transition mandates, it is perhaps what is missing from NCLB that is most impactful. The NCLB focus has been primarily related to improved accountability for academic achievement, which is an important predictor of postschool outcomes. Yet the NCLB does recognize the need for transition educational services except for youths in correctional facilities or institutions for neglected youths. The lack of focus on transition education opportunities for all children, including those with disabilities, does not spur development of comprehensive transition education opportunities. Research suggests that students with disabilities benefit from access to programs that focus on both academic and functional skill development needed for success in adulthood.

Relative to transition education and IDEIA, research has demonstrated that federal transition mandates have not been fully and consistently implemented. Youths from low socioeconomic backgrounds and youths living in urban settings may be particularly vulnerable to delays in transition education, because they attend schools most likely to be staffed by inexperienced and uncertified teachers who may lack awareness of policy. GilKashiwabara and colleagues (2007) identified an additional conflict for youths with disabilities who also receive foster care services, citing clear differences between programmatic requirements in special education and the foster care system resulting in multiple and disconnected transition plans.

Ensuring that students with disabilities have access to general education curricula has also been defined as one of several challenges in transition education (Johnson et al., 2002). Only $37 \%$ of African American youths with disabilities spend the majority of the school day in the general education classroom, compared with $53 \%$ of European American youths with disabilities who receive services in general education settings (U.S. Department of Education, 2004). Of students with emotional and cognitive disabilities, categories for which overrepresentation of African American males has consistently been documented, $15 \%$ and $25 \%$, respectively, receive all secondary instruction in special education settings (U.S. Department of Education, 2004). The implementation of transition policy has been an effective force in systemic change (Kohler \& Field, 2003); however, few studies have focused on the implementation of policy as it pertains to the treatment of subgroups of individuals with disabilities. Research on multicultural transition issues 
has not sufficiently considered exo-level interactions to provide a deep understanding of transition outcomes of diverse youths with disabilities.

\section{Macrosystem}

The macrosystem consists of societal-level interactions. This all-encompassing term can be conceptualized as a social blueprint and includes patterns of activities that occur within and influence the exo, meso, and micro levels. Societal forces such as the regional, national, and global economies; participation of the United States in the globalization of intellectual development, labor, and trade; and the relationships among subgroups of the U.S. population influence, and are influenced by, interactions within each of the levels of the ecological model. Values and beliefs that influence our (in)tolerance for one another and result in individual and institutional acts of bias and discrimination are another important aspect of the macrocultural system (Garcia \& Dominguez, 1997; Gil-Kashiwabara et al., 2007). Although diverse students with disabilities may not be principal actors in macrosystemic contexts, they are certainly influenced by these forces.

One example of a macrosystemic influence is immigration and transnationalism, or travel of people between Mexico and other countries and the United States for the purpose of finding work, seeking educational opportunities, or obtaining political asylum (Trueba, 1999). This influx of workers and their children has contributed to the cultural and linguistic diversity of U.S. classrooms. In 2004, $19 \%$ of U.S. elementary students spoke languages other than English at home (National Center for Educational Statistics [NCES], 2005). To respond to this changing population, the U.S. education system must cultivate a teacher force that effectively works with families and students, including those with disabilities, from a variety of cultural and linguistic backgrounds. The documentation status of immigrant children with disabilities also complicates an already complex set of criteria for obtaining vocational rehabilitation, social security income, adult social services, and support for postsecondary education (Losen \& Orfield, 2002).

National employment trends represent another macrosystemic issue that affects transition education and outcomes for diverse youths with disabilities. Although employment rates for women and men have been similar during the past two decades, women continue to earn lower average hourly wages than men (Bureau of Labor Statistics, 2006). Transition outcomes for young women with disabilities are affected by the economic realities existing in the macrosystem. Many young women with disabilities face workforce barriers by virtue of being female (Lindstrom, Benz, \& Doren, 2004). Unemployment figures also remain disproportionately high for African Americans who comprise $11 \%$ of the labor force yet represent $22 \%$ of people who are unemployed (Bureau of Labor Statistics, 2006). African Americans and Latinos also hold fewer managerial or professional positions than European or Asian Americans. These national trends inform federal and state policies regarding education and employment and influence teachers' perceptions of community members' employability.

Special education transition research typically includes discussions of macrosystemic issues as tangential to micro- and mesosystemic foci. Rueda, Monzo, Shapiro, Gomez, and Blacher (2005) addressed U.S. macrocultural conceptions of worker identities as compared to the conceptualizations of Latina mothers of children with developmental disabilities; however, they focused on the microcultural values and beliefs about independence and individualism. Other studies that have documented multicultural parents' transition-related values and beliefs and diverse students' transition attitudes, knowledge, and skills highlight primarily micro- and mesosystemic questions. A greater understanding of macrosystemic interactions is sorely needed to increase our understanding of all levels of the ecological model of transition education.

\section{Future Directions for Research and Practice}

Given the complex and pressing needs of diverse youths with disabilities, we believe a clear agenda exists to improve research and practice. As DCDT members, we must define the issues and develop effective instructional interventions and support systems to improve postschool outcomes for youths with disabilities from low socioeconomic backgrounds; those who are African American, Latino, Native American Indian; as well as youths who speak English as a second language and face documentation and immigration issues. We must consider and address all levels of the ecological model in developing programs and educational policies. Although we may begin by addressing inequities in our own school systems, we must also advocate for changes in political, economic, and social structures. Existing systems are simply not working effectively for many youths with disabilities; we need an ecological approach that will lead us from economic and social marginalization toward maximizing opportunities. To emphasize the need to focus on broader ecological contexts, we begin with macrosystem-level concerns and work inward, toward the micro-level implications. 


\section{Macro-Level Implications}

By acknowledging the complex sociocultural, political, and historical contexts in which transition education occurs, DCDT members need to expand research efforts to include interactions among and between the ecologies of transition education. We must be aware of larger social and system-level trends and issues (e.g., employment rates, population demographics, etc.) and incorporate those forces into our investigations and intervention efforts. Careful attention to detail regarding systemic change and equity are necessary to move transition education forward so that we address the needs of all youths with disabilities, including those who may be harmed by structures that privilege some over others.

In practice, it is no simple task to address large-scale social issues such as poverty and unemployment. However, these macrosystemic realities play a critical role in limiting opportunities for youths with disabilities from diverse groups. All of us share the responsibility of advocacy, addressing social and political issues that will affect national, state, and local levels.

\section{Exo-Level Implications}

In Kohler's (1996) transition taxonomy, the structure and characteristics of transition education philosophy, programs, and policies are considered integrally important to postschool outcomes. Federal and state transition policies must be examined to determine the extent to which their intended mandates reach groups of youths with disabilities who often face marginalization as a result of living in poverty; speaking English as a second language; immigration status; or experience discrimination based on race/ethnicity, gender, and sexual orientation. To what extent does national policy address unique challenges faced by diverse youths with disabilities? How might technical and financial support be filtered to address the needs of youths facing challenges associated with disability and marginalization?

Another aspect of systemic change at the exo level is the diversification of the U.S. teaching force, which has remained largely homogeneous. Approximately $90 \%$ of elementary teachers are female, as are $75 \%$ of secondary teachers (National Center for Education Statistics, 2005, p. 3). Teachers of European American descent comprise $60 \%$ of the teaching force (National Collaborative on Diversity in the Teaching Force, 2004). We need to recruit and retain diverse professionals who can provide effective services within local schools as well as become leaders in transition education. A diverse teaching force has the potential to expand our capacity to respond to diverse youths' preferences, strengths, and needs.

\section{Meso- and Micro-Level Implications}

To date, transition researchers have provided ample evidence of the important intercultural differences that affect transition education. We are advocating for systematic changes in both research and practice that will lead to more equitable postschool outcomes. We need to begin by identifying programmatic characteristics that predict postschool employment and engagement. Studies have illuminated school and community barriers faced by diverse youths and families (Harry, 2002), young women with disabilities (Lindstrom et al., 2004), and youths from families of low socioeconomic status (Park, Turnbull, \& Turnbull, 2002). The NLTS2 provides a wealth of data across disability and demographic variables; however, these results provide a mixed picture of the relationship between ethnicity, gender, socioeconomic class, and outcomes (Wagner, Newman, Cameto, Garza et al., 2005). More investigation is warranted using this and other large-scale data sets to disentangle variables that influence transition experiences and opportunities. Without this breadth and scope of knowledge, we will likely produce solutions that fail to address both inter- and intragroup differences and lack the capacity to be as dynamic as the identities of the youths we serve.

In practice, it is critical that DCDT members develop and test school- and community-based interventions designed to improve transition education, support services, and subsequent postschool outcomes with pointed attention to the needs of diverse youths with disabilities who experience economic and other postschool challenges. The potential of self-determination skill instruction and enhanced opportunities for its practice across diverse groups of youths must be a particular focus of our investigations. Diverse youths with disabilities have not been adequately served by existing programs (Harry, 2002; Trainor, 2005). DCDT needs to create best practice programs and services that address the unique needs of diverse youths with disabilities, are carefully evaluated and documented to be effective, and can be replicated across settings.

In addition, DCDT needs to develop and evaluate professional development to increase cultural competence among transition education personnel. Educators must consider students' culture and community in transition planning and services delivery (Harry, 2002; Rueda et al., 2005). Professionals also need to develop a more sophisticated understanding of school, family, and community issues and barriers and be provided with ongoing training to increase awareness, knowledge, and specific skills (Lichtenstein, Lindstrom, \& Povenmire-Kirk, in press; Smith, Constantine, Dunn, Dinehart, \& Montoya, 
2006). We need to identify effective instructional strategies and techniques that lead to improved teacher and service provider competence.

Directing research and practice toward an ecological path of study is no easy endeavor; however, to do so provides the opportunity to develop strategies that uncover the complexity of real-life interactions and avoid deficit notions of individuals with disabilities. As a field, we must carefully consider cultural, political, economic, and social contexts; develop multidimensional transition education strategies; and advocate for systemic changes that promote positive postschool outcomes.

\section{References}

Asch, A., Rousso, H., \& Jefferies, T. (2001). Beyond pedestals: The lives of girls and women with disabilities. In H. Russo \& M. Wehmeyer (Eds.), Double jeopardy: Addressing gender equity in special education (pp. 289- 312). Albany: SUNY Press.

Banks, J. A. (2004). Race, knowledge construction, and education in the United States: Lessons from history. In J. A. Banks \& C. A. McGee Banks (Eds.), Handbook of research in multicultural education (2nd ed., pp. 228-239). San Francisco: Jossey-Bass.

Benz, M., Johnson, D., Mikkelsen, K., \& Lindstrom, L. (1995). Improving collaboration between schools and vocational rehabilitation: Stakeholder identified barriers and strategies. Career Development for Exceptional Individuals, 18, 133-144.

Blustein, D. L., Chaves, A. P., Diemer, M. A., Gallagher, L. A., Marshall, K. G., Sirin, S., et al. (2002). Voices of the forgotten half: The role of social class in the school-to-work transition. Journal of Counseling Psychology, 49, 311-323.

Bronfenbrenner, U. (1979). The ecology of human development: Experiments by nature and design. Cambridge, MA: Harvard University Press.

Brown, S. E. (1996). We are who we are. So who are we? Mainstream, 20(10), 28-31.

Bureau of Labor Statistics. (2006). Charting the U.S. labor market in 2005. Washington, DC: U.S. Department of Labor.

Chronister, K. M., McWhirter, B. T., \& Kerewsky, S. D. (2004). Counseling and ecological prevention practice. In R. K. Coyne \& E. P. Cook (Eds.), Ecological counseling: An innovative approach to conceptualizing person-environment interaction (pp. 315-338). Alexandria, VA: ACA Press.

Coutinho, M. J., Oswald, D. P., \& Best, A. M. (2006). Difference in outcomes for female and male students in special education. Career Development for Exceptional Individuals, 29, 48-59.

deFur, S. H., Todd-Allen, M., \& Getzel, E. E. (2001). Parent participation in the transition planning process. Career Development for Exceptional Individuals, 42, 19-36.

Delpit, L. D. (1995). Other people's children: Cultural conflict in classrooms. New York: Norton.

Garcia, S. B., \& Dominguez, L. (1997). Cultural contexts that influence learning and academic performance. Child and Adolescent Psychiatric Clinics of North America, 6, 621-655.

Geenen, S. J., Powers, L. E., \& Lopez-Vasquez, A. (2005). Barriers against and strategies for promoting the involvement of culturally diverse parents in school based transition planning. Journal for Vocational Special Needs Education, 27(3), 4-14.
Gil-Kashiwabara, E., Hogansen, J., Geenen, S. J., Powers, K. M., \& Powers, L. E. (2007). Improving transition outcomes for marginalized youth. Career Development for Exceptional Individuals, 30, 80-91.

Goldberg, R. J., Higgins, E. L., Raskind, M. H., \& Herman, K. L. (2003). Predictors of success in individuals with learning disabilities. Learning Disabilities Research \& Practice, 18, 222-236.

Greene, G., \& Nefsky, P. (1999). Transition for culturally and linguistically diverse youth with disabilities: Closing the gaps. Multiple Voices for Ethnically Diverse Exceptional Learners, 3(1), 15-24.

Harry, B. (2002). Trends and issues in serving culturally diverse families of children with disabilities. Journal of Special Education, 36, 131-138.

Harry, B., Allen, N., \& McLaughlin, M. (1995). Communication versus compliance; African-American parents' involvement in special education. Exceptional Children, 61, 364-377.

Harry, B., \& Klingner, J. (2006). Why are so many minority students in special education? New York: Teachers College Press.

Individuals With Disabilities Education Improvement Act of 2004, Pub. L. No. 108-446.

Johnson, D. R., Stodden, R. A., Emanuel, E. J., Luecking, R., \& Mack, M. (2002). Current challenges facing secondary education transition services: What research tells us. Exceptional Children, 68, 519-531.

Kalyanpur, M., Harry, B., \& Skrtic, T. (2000). Equity and advocacy expectations of cultural diverse families' participation in special education. International Journal of Disability, Development and Education, 47, 119-136.

Kohler, P. D. (1996). Taxonomy for transition programming. Urbana-Champaign, IL: University of Illinois, Transition Research Institute.

Kohler, P. D., \& Field, S. (2003). Transition-focused education: Foundation for the future. Journal of Special Education, 37, 174-183.

Konrad, M., Fowler, C. H., Walker, A. R., Test, D. W., \& Wood, W. M. (2007). Effects of self-determination interventions on the academic skills of students with learning disabilities. Learning Disabilities Quarterly, 30(2), 89-113.

Leake, D., \& Boone, R. (2007). Multicultural perspectives on selfdetermination from youth, parent, and teacher focus groups. Career Development for Exceptional Individuals, 30, 104-115.

Lichtenstein, D., Lindstrom, L., \& Povenmire-Kirk, T. (in press). Promoting multicultural competence: Diversity training for transition professionals. Journal for Vocational Special Needs Education.

Lindstrom, L., \& Benz, M. (2002). Phases of career development: Case studies of young women with learning disabilities. Exceptional Children, 69, 67-83.

Lindstrom, L., Benz, M. R., \& Doren, B. (2004). Expanding career options for young women with disabilities. Career Development for Exceptional Individuals, 27, 43-63.

Losen, D. J., \& Orfield, G. (2002). Racial inequity in special education. Cambridge, MA: Harvard Education Press.

Martin, J. E., \& Marshall, L. (1995). ChoiceMaker: A comprehensive self-determination transition program. Intervention in School and Clinic, 30, 147-156.

Martin, J. E., Van Dycke, J. L., Christensen, W. R., Greene, B. A., Gardner, J. E., \& Lovett, D. L. (2006). Increasing student participation in their transition IEP meetings: Establishing the SelfDirected IEP as evidenced-based practice. Exceptional Children, 72(3), 299-316. 
McCray Sorrells, A., Webb-Johnson, G., \& Townsend, B. L. (2004). Multicultural perspectives in special education. In A. McCray Sorrells, H. Rieth, \& P. T. Sindelar (Eds.), Critical issues in special education (pp. 73-91). Boston: Pearson.

Mithaug, D. E. (1996). Equal opportunity theory. Thousand Oaks, CA: Sage.

National Center for Education Statistics. (2005). Special analysis: Mobility in the teacher workforce. In The condition of education 2005 (p. 3). Washington, DC: U.S. Department of Education.

National Collaborative on Diversity in the Teaching Force. (2004). Assessment of diversity of America's teaching force. Washington, DC: Author.

Neal, L. I., McCray, A. D., Webb-Johnson, G., \& Bridgest, S. T. (2003). The effects of African American movement styles on teachers' perceptions and reactions. Journal of Special Education, $37,49-57$.

Park, J., Turnbull, A., \& Turnbull, H. (2002). Impacts of poverty on quality of life in families of children with disabilities. Exceptional Children, 68, 151-170.

Rueda, R., Monzo, L., Shapiro, J., Gomez, J., \& Blacher, J. (2005). Cultural models of transition: Latina mothers of young adults with developmental disabilities. Exceptional Children, 71(4), 401-414.

Sarver, M. D. (2000). A study of the relationship between personal and environmental factors bearing on self-determination and the academic success of university students with learning disabilities. Unpublished doctoral dissertation, University of Florida, Gainesville.

Shogren, K. A., Wehmeyer, M. L., Palmer, S. B., Soukup, J. H., Little, T. D., Garner, N., et al. (2007). Examining individual and ecological predictors for the self-determination of students with disabilities. Exceptional Children, 73, 488-509.

Sickmund, M. (2004, June). Juvenile offenders and victims: National report series bulletin. Washington, DC: U.S. Department of Justice.

Smith, T., Constantine, M., Dunn, T., Dinehart, J., \& Montoya, J. (2006). Multicultural education in the mental health professions: A metaanalytic review. Journal of Counseling Psychology, 53, 132-145.

Trainor, A. A. (2005). Self-determination perceptions and behaviors of diverse students with LD during the transition planning process. Journal of Learning Disabilities, 38, 233-249.

Trainor, A. A. (2007). Perceptions of adolescent girls with LD regarding self-determination and postsecondary transition planning. Learning Disability Quarterly, 30, 31-45.

Trueba, E. T. (1999). Latinos unidos: From cultural diversity to the politics of solidarity. Lanham, MD: Rowman \& Littlefield.

U.S. Department of Education. (2003, October). Dropout rates in the United States: 2002 and 2003. Washington, DC: Government Printing Office. Retrieved August 17, 2007, from http://nces.ed.gov/ pubs2006/dropout/tables/table_9A.asp?referrer=report

U. S. Department of Education. (2004). Twenty-sixth annual report to Congress on the implementation of the IDEA. Washington, DC: Author.

U.S. Department of Education. (2006). Racial/ethnic distribution of public school students. In The condition of education 2006 (pp. 116-118). Washington, DC: Author.
U.S. Department of Education. (2007). Contexts of elementary and secondary education. In The condition of education 2007 (pp. 62-73). Washington, DC: Author.

Valenzuela, R. L., \& Martin, J. E. (2005). Self-directed IEP: Bridging values of diverse cultures and secondary education. Career Development for Exceptional Individuals, 28(1), 4-14.

Wagner, M., Newman, L., Cameto, R., Garza, N., \& Levine, P. (2005). After high school: A first look at the post-school experiences of youth with disabilities. Menlo Park, CA: SRI.

Wagner, M., Newman, L., Cameto, R., \& Levine, P. (2005). Changes over time in the early post-school outcomes of youth with disabilities. Menlo Park, CA: SRI International.

Wehmeyer, M. L., Agran, M., \& Hughes, C. (2000). A national survey of teachers' promotion of self-determination and studentdirected learning. Journal of Special Education, 34, 58-68.

Wehmeyer, M. L., \& Palmer, S. B. (2003). Adult outcomes for students with cognitive disabilities three-years after high school. Education and Training in Developmental Disabilities, 38(2), 131-144.

Audrey A. Trainor, $\mathrm{PhD}$, is an assistant professor of special education at the University of Wisconsin-Madison. Her current interests include multicultural special education issues, postsecondary transition planning for students with high incidence disabilities, family and student participation in special education, and English language learners diagnosed with disabilities.

Lauren Lindstrom, $\mathrm{PhD}$, is an assistant professor and senior research associate in the College of Education at the University of Oregon. Her areas of expertise include career development, gender equity, transition planning, and postschool outcomes for youths with disabilities.

Marlene Simon-Burroughs, $\mathrm{PhD}$, is an associate director in the Research to Practice Division of the U.S. Department of Education's Office of Special Education programs, providing leadership for discretionary investments in secondary education, transition, and postsecondary outcomes.

James E. Martin, $\mathrm{PhD}$, holds the Zarrow Chair in Special Education and directs the Zarrow Center at the University of Oklahoma. His professional interests include self-determination and transition education practices to improve high school and postsecondary outcomes, especially higher education and employment.

Audrey McCray Sorrells, Ph.D., is an associate professor of Special Education and Fellow in the Lee Hage Jamail Regents Chair in Education at The University of Texas at Austin. Her research interests include African American disproportionality in special education, professional development and research-based reading interventions for diverse middle school environments. 